\title{
SISTEM ZA IZDELAVO DIGITALNEGA ORTOFOTA NA PC
}

\author{
Tomaž Gvozdanović
}

Izvleček

UDK 528.7

Digitalni ortofoto postaja $v$ svetu osnovni sloj GIS-ov. Izdelava digitalnega ortofota temelji na razpačevanju digitalnih slik aeroposnetkov, ki predstavljajo ogromne količine podatkov. Trenutno poznane operacionalne rešitue temeljijo na delovnih postajah in specialni strojni opremi. $V$ referatu je predstavljen sistem, ki je plod domačega znanja, in je operacionalen na močnejših PC računalnikih. Poudarek je na reševanju problemov $v$ zvezi s hranjenjem, prenosi in obdelavo digitalnih slik. Sistem je namenjen predusem izdelavi digitalnega ortofota, ki glede natančnosti ustreza TTN5 oziroma TTN10 in je kot tak interesanten za najširši krog uporabnikov.

\section{Abstract}

UDC 528.7

THE SYSTEM FOR THE GENERATION OF DIGITAL ORTHOPHOTO ON PC

Digital orthophoto is today becoming the main layer in the GIS data base. Digital orthophoto generation is based on the diferential rectification of digital images and means processing large amounts of data. So today's solutions are ba sed on workstations and special hardware. This article presents sytems which is based on high-end PC computers. The point was on solving problems about storage, transfer and processing of digital images. System supports specially digital orthophoto generation, which accuracy is comparable with the accuracy of our 1:5000 system maps.

\section{DIGITALNI ORTOFOTO}

Z naraščajočimi zmogljivostmi računalniške opreme in razvojem novih hitrejših postopkov, je postala izdelava nekaterih fotogrametričnih produktov tako ekonomična, da je ceneje podatke zajeti na novo, kot pa jih vzdrževati. Ekonomičnost postopkov in s tem cena fotogrametričnih produktov pa spreminjajo tudi miselnost in zahteve uporabnikov.

Posnetki združujejo zelo veliko informacij. Njihova pomanjkljivost pa je, da je vsebina popačeno prikazana. Če poznamo obliko terena, lahko posnetek

Mag. Tomaž Gvozdanović, Slovenska 51 a, 61000 Ljubljana 
razpačimo. Tak posnetek imenujemo orto posnetek oziroma ortofoto. V dobi analitične fotogrametrije so ortofoto, izdelovali $z$ računalniško krmiljenimi razpačevalniki, ki temeljijo na optični preslikavi posnetka na film, se pravi analogno obliko. Rezultat postopka digitalne fotogrametrije pa je razpačena digitalna slika oziroma digitalni ortofoto. Do nedavnega je izraz digitalni ortofoto pomenil samo razpačen digitalni posnetek, danes pa uporabljamo ta izraz tudi za digitalno sliko, ki je sestavljena iz več razpačenih digitalnih posnetkov.

Izraz "izdelava digitalnega ortofota" lahko razumemo na dva načina :

- končni rezultat je digitalna slika, ne glede na kakšen način smo izvedli razpačevanje; dopuščena je tudi možnost, da izdelamo na analognem ali analitičnem instrumentu ortofoto $v$ analogni obliki (na film ali papir) in ga nato skaniramo; ta način lahko smatramo za hibridnega, s stališča ekonomičnosti pa ni smiseln,

- postopek razpačevanja izvajamo na digitalnih slikah, namesto drage fotogrametrične opreme pa potrebujemo le računalnik; zato menim, da si le ta način zasluži, da ga imenujemo "izdelava digitalnega ortofota".

Ker so sistemi na ključ precej dragi in zahtevajo močno strojno opremo smo se odločili, da sami oblikujemo sistem za izdelavo ortofota. Po analizi količine podatkov in zato porabljenega časa, smo ugotovili, da današnji PC-ji popolnoma zadostujejo, rešiti moramo le problem hranjenja in prenosa velikih digitalnih slik.

\section{POSTOPEK IZDELAVE DIGITALNEGA ORTOFOTA}

Izdelava digitalnega ortofota poteka v 8 fazah. Aerosnemanje je predpogoj za izdelavo ortofota, saj $v$ tej fazi dobimo posnetke. Pri nas je stanje glede posnetkov dokaj ugodno, saj ciklično aerosnemanje zagotavlja posnetke, ki so stari največ 2 do 3 leta, kar je $v$ primeru $z$ načrti bistveno ažurneje. Poleg cikličnih aerosnemanj se izvajajo po potrebi tudi druga snemanja $v$ večjih merilih ter $\mathrm{v}$ barvni ali infrardeči tehniki.

Digitalizacija (skaniranje) posnetka, dobljenega $z$ aerosnemanjem, nam da osnovni vhodni podatek za izdelavo ortofota - digitalno sliko; pri skaniranju določimo splošne lastnosti slike, $z$ izbiro geometrične (dimenzija piksla) in radiometrične resolucije (razpon barvnih vrednosti).

Predprocesiranje, obsega obdelave slik, ki $\mathbf{v}$ osnovi s samo fotogrametrijo nimajo nič skupnega; v tej fazi želimo izboljšati kvaliteto digitalne slike, predvsem $\mathrm{v}$ dveh pogledih: $\mathrm{z}$ odpravljanjem šumov nastalih pri skaniranju in prenosih ter $\mathrm{z}$ izboljšavo kontrasta.

Digitalni model reliefa je ključnega pomena pri izdelavi ortofota, saj predstavlja prostorsko ploskev s katero sekamo žarke, da dobimo prostorske 
točke. Model seveda lahko že obstaja, pogostokrat pa ga moramo za dano območje še izdelati. Izdelava digitalnega modela reliefa iz načrtov je najhitrejši in najcenejši način, pogoj pa je, da obstajajo načrti $z$ višinsko predstavo ustrezne kvalitete.

Absolutna orientacija posnetka opisuje položaj kamere, glede na prostorski koordinatni sistem $\mathrm{v}$ trenutku ekspozicije. Absolutno orientacijo za potrebe izdelave ortofota izračunamo na podlagi oslonilnih točk, v kolikor pa že obstaja (če je bila izračunana v okviru aerotriangulacije), jo lahko privzamemo.

Razpačevanje je faza v kateri vsakemu pikslu izhodne slike določimo njegovo originalno pozicijo na posnetku. Za hitrejše delo so $\mathrm{v}$ svetu razvili rešitev, pri kateri transformiramo le manjše število tako imenovanih sidrnih točk, vse ostale vmesne točke (piksle) pa interpoliramo na osnovi okoliških sidrnih točk. S tem za večino točk izvedemo direktno preslikavo med koordinatnim sistemom vhodne in izhodne slike, brez transformacij $v$ slikovni in prostorski koordinatni sistem Radiometrični del postopka - prirejanje sivine $\mathrm{v}$ geometričnem postopku izračunani lokaciji, izvedemo $\mathrm{v}$ praksi $z$ eno od sivih interpolacij (najbližji sosed, bilinearna interpolacija, bikubična interpolacija).

Postprocesiranje ortofota je odvisno od zahtev uporabnika, predvsem zahtev glede območja, namembnosti ortofota, uporabnikovih računalniških zmogljivosti, zahtevanega merila itd. Najpomembnejše je geometrično in radiometrično usklajevanje ortofoto posnetkov, ki je potrebno, kadar $z$ enim samim posnetkom ne moremo pokriti vsega zahtevanega območja.

Izris digitalnega ortofota pomeni ponovno pretvorbo $\mathrm{v}$ digitalno obliko. Izris je zanimiv predvsem $\mathrm{v}$ obliki ortofoto karte, $\mathrm{ki}$ je $\mathrm{z}$ dodatno vsebino (napisi, izolinije, okvirna vsebina ...) opremljen ortofoto. Ta faza pri nekaterih aplikacijah, kjer ortofoto uporabljamo le $\mathrm{v}$ njegovi digitalni obliki (prikazovanje na ekranu) popolnoma odpade.

\section{STROJNA OPREMA}

Celotni sistem za izdelavo ortofota je zasnovan tako, da je možna njegova implementacija na boljšem osebnem računalniku. Spodnja meja smiselnosti je 25 ali 33 megaherčni 386 računalnik z vsaj 4 Mb RAM-a in vsaj 100 MB trdim diskom. Priporočljiv je seveda računalnik, zgrajen okrog 486 procesorja $(25,33$ ali $50 \mathrm{MHz}) \mathrm{s}$ čim več RAM-a (16 do $64 \mathrm{Mb})$. Tudi disk naj bo, če nameravamo združevati več posnetkov, velik vsaj nekaj $100 \mathrm{Mb}$. Morda so take zahteve danes visoke, vendar bodo $v$ letu ali dveh postale nekaj čisto vsakdanjega.

Za skaniranje slike lahko uporabimo pravzaprav katerikoli skaner, seveda pa si moramo biti na jasnem, da je kvaliteta končnega izdelka direktno 
odvisna od digitalne slike posnetka. Ročni skanerji so popolnoma neprimerni, tudi namizni in samostoječi skanerji so se izkazali za premalo natančne. Tako nam ostanejo le specialni skanerji, ki so ekonomsko upravičeni le pri izdelavi ortofota za celo državo, ali pa skanerji, ki jih imajo grafična podjetja. Slednje se izkaže kot dokaj ekonomična rešitev, saj je nabava lastnega skanerja $\mathrm{z}$ resolucijo od 600 do 2000 dpi upravičena šele pri skaniranju 2- 3000 posnetkov.

Izhodna enota, če se ne zadovoljimo samo s prikazom ortofota na računalniškem ekranu, ampak želimo imeti rezultat na papirju, se imenuje fotoploter in je izredno draga. Tudi tu smo uporabili opremo grafičnih podjetij, ki imajo zelo kvalitetne fotoploterje. Standardna resolucija za izris je $300 \mathrm{dpi}$, v kolikor želimo izrisano sliko povečati pa mora biti tudi resolucija ustrezno večja.

Precejšen problem ali pa vsaj veliko porabo časa predstavlja prenos velike količine podatkov $z$ mesta skaniranja na mesto obdelave in na koncu na mesto izrisa. Ker so sistemi različnih izdelovalcev, so različni tudi spominski mediji in formati zapisa. Za prenos podatkov lahko uporabljamo:

- DAT-digital audio tape,

- magnetno-tračne enote ("streamer"),

- optične diske,

- magnetno optične diske,

- prenosljive trde diske.

Zaradi precejšnjih spominskih kapacitet in kratkih dostopnih časoviso danes zelo aktualni optični in magnetno-optični diski.

\section{PROGRAMSKA OPREMA}

Programski paket $\mathbf{s}$ katerim bo mogoče izdelati ortofoto, je še $\mathbf{v}$ fazi prototipa, ki pa je že operativen, kar kaže testni primer. Na osnovi analize zahtev in izkušenj s prototipom smo postavili naslednje smernice za razvoj programskega paketa:

- vsako izdelavo ortofota obravnavamo kot projekt, ki ima svoje vhodne podatke in svoje rezultate; programski paket mora omogočati pregledno vodenje projekta $z$ izpisi in statistikami, sem pa sodi tudi organizacija podatkov po direktorijih in sistematična nomenklatura datotek,

- programski paket mora omogočati tri načine dela: interaktivni, kjer program operacijo izvede le na uporabnikov ukaz, polavtomatski, pri kateri se potek dela ustavi samo na nekaj mestih, kjer je potrebna uporabnikova akcija, in avtomatski način, pri katerem mora uporabnik samo definirati območje ortofota in identificirati oslonilne točke,

- pri razpačevanju posnetka mora paket omogočati delo po blokih s projektivno transformacijo in bilinearno transformacijo, za interpolacijo sivih 
vrednosti pa mora podpirati metodo najbližjega soseda ter bilinearno in bikubično interpolacijo,

- programska oprema naj čim bolje izkorišča zmogljivost strojne opreme, predvsem optimalno uporabo spomina, kar lahko bistveno zmanjša obseg dela $z$ diskom in skrajša čase obdelav,

- paket mora podpirati standardne formate za izmenjavo slik (npr. TIFF), kar prinaša kompatibilnost $\mathrm{z}$ mnogimi komercialnimi programskimi paketi,

- paket naj bi omogočal delo s komprimiranimi slikami, kar lahko bistveno zmanjša potrebni prostor na disku.

Ni potrebno, da programski paket podpira izdelavo DMR, saj za to obstaja mnogo dobrih paketov. Mora pa biti $\mathrm{v}$ paket vključen program za manipulacijo $\mathbf{s}$ temi podatki in $\mathrm{za}$ konverzijo iz standardnih formatov.

Popolna komercialna verzija programskega paketa za izdelavo digitalnega ortofota, ki bo izpolnjevala vse zgoraj omenjene zahteve, bo izdelana $\mathrm{v}$ roku nekaj mesecev.

\section{KOLIČINA PODATKOV}

Največji problem je pravzaprav količina podatkov, ki nastopajo $\mathrm{v}$ obliki digitalnih slik. Le-te lahko delimo na :

- vhodne slike (skanirani aeroposnetki),

- izhodne slike (ortofoto)

- delovne slike (predprocesiranje , razpačevanje,...)

Pri standardni velikosti posnetka $25 \times 25 \mathrm{~cm}$ (uporabne površine približno $9 \times 9$ inčev), ki je pri nas najpogostejša, so pri izbranih resolucijah vhodne digitalne slike velike :

$\begin{array}{rr}\text { dpi } & \text { Mb } \\ 100 & 1 \\ 300 & 7 \\ 600 & 29 \\ 800 & 52 \\ 1000 & 81\end{array}$

Za kvadratni kilometer zemeljske površine je pri izbranem merilu 1:5000 (kar pomeni velikosti piksla $0.1 \mathrm{~mm}$ oziroma $0.5 \mathrm{~m} \mathrm{v}$ naravi) velikost izhodne slike $4 \mathrm{Mb}$, oziroma $27 \mathrm{Mb}$ za en list 1:5000.

Omenjene količine veljajo za črno bele 8 -bitne slike. Za barvne slike, je količina podatkov 3-krat večja.V splošnem je skupna količina vseh slikovnih podatkov 3-10 krat večja od izhodne slike. 
Zoper tolikšne količine podatkov uporabljamo dvoje orožij:

- medije za shranjevanje,

- komprimiranje.

Mediji, ki jih uporabljamo za shranjevanje so predvsem magnetno-optični in optični izmenljivi diski, ki poleg velike kapacitete $(600 \mathrm{Mb}$ oziroma lGB), omogočajo tudi dokaj enostavno in hitro delo.

Za komprimiranje digitalnih slik uporabimo JPEG standard. JPEG komprimiranje zmanjša količino podatkov za faktor 5-10, v kolikor se lahko sprijaznimo $z$ malo slabšo sliko pa tudi do 20. Vsekakor je faktor komprimiranja bistveno večji, kot pri uporabi standardnih programov za komprimiranje podatkov (PKZIP, LHA, ARJ...), saj le ti dosegajo ponavadi faktor manj kot 2. Hitrost komprimiranja je na 486/25 računalniku približno 2.5 do $3.5 \mathrm{Mb}$ na minuto.

\section{TESTNI PRIMER}

Za testni primer smo izdelali ortofoto, ki ga pokriva en načrt TTN 5, sestavljen pa je iz 4 posnetkov. Velikost piksla $v$ naravi je $0.5 \times 0.5 \mathrm{~m}$, kar pomeni, da je izhodna slika (siva,8- bitna) velika $27 \mathrm{Mb}$.

Količina podatkov pri skaniranju s 700 dpi je bila za vse 4 posnetke 150 $\mathrm{Mb}$. Podatke smo prenesli na PC računalnik $z$ magnetno optičnimi diski. Orientacijo posnetkov smo določili na podlagi oslonilnih točk. Slikovne koordinate le-teh smo izmerili na Dicometru, njihove prostorske koordinate pa smo dolčili iz načrtov in DMR. Uporabljeni DMR je bil $v$ obliki pravilnega grida na $25 \mathrm{~m}$. Orientacijo posnetkov smo določili s fotogrametričnim urezom, izboljšali pa smo jo $z$ izravnavo s snopi.

Razpačevanje na računalniku PC 486/25 (16 Mb RAM) je trajalo pri uporabi bikubične sive interpolacije 40 minut. Geometrično in radiometrično usklajevanje posnetkov je potekalo popolnoma avtomatsko trajalo, pa je 20 minut.

\section{ZAKLJUČEK}

Testni primer je pokazal, da se $\mathrm{v}$ svojih predvidevanjih nismo zmotili in da je izdelava ortofota na PC-jih ne samo mogoča, ampak tudi ekonomična. Že prototip sistema (ob optimalnih pogojih) omogoča izdelavo ortofota iz enega posnetka, od skaniranja do izrisa $v$ manj kot 8 urah. Ob dejstvu, da vse skupaj deluje na PC-ju, in da za skaniranje in izrise plačamo uslugo, bo sistem $\mathrm{v}$ komercialni obliki cenovno dostopen širokemu krogu uporabnikov, kar lahko precej prispeva $\mathrm{k}$ uveljavitvi digitalnega ortofota pri nas. 